\title{
Arab Countries Can Perform Better with Clear Emphasis on Innovation, Entrepreneurship and an Evolving Culture
}

\author{
M-Said Oukil
}

\begin{abstract}
Arab countries strive to integrate the international business and close the gaps with the rest of the world as quickly as possible. However, a real problem is that compared to other countries, their policies lack many important ingredients for success. Gaining competitive advantage and achieving growth and competitiveness are not only a matter of openess, huge investments and business creation per se. Researchers argue that changes in management and governance are a must, and emphasis on innovation and entrepreneurship, and improving the business culture through education are very critical. In this paper, the author considers the case of the Arab countries, using secondary data and drawing on relevant academic work. The results of his study suggest that despite some important achievements, there are specific challenges facing these countries to make a sound shift towards productive and dynamic economies and better societies.After an introduction and literature review, section III provides a broad picture of the overall progress made by Arab countries, followed by main shortcomings. Section IV elaborates on the necessity of focusing on monitoring people's initiatives, and enhancing entrepreneurship at all levels. Section $V$ discusses the inadequate understanding of competitiveness in Arab countries. Section VI describes the prevailing loose business culture in these countries. Section VII discusses the particular role of higher education institutions. The last section concludes the paper.
\end{abstract}

Index Terms-Arab countries, business culture entrepreneurship education, innovation, international integration.

\section{INTRODUCTION}

Globalization has put more and more pressure on all economies and organizations, pushing them to rapidly evolve, and effectively integrate into the international world of business. In this context, the outcomes, obtained through innovation, entrepreneurship and education, by developed, newly industrialized and emerging countries, provide great impetus for imitation and prompt action by the whole Arab world.

Overall, Arab countries are very rich, not only in terms of raw materials and financial surplus, but also in human potentialities and innovation capital. A number of achievements, including real progress in traditional and

Manuscript received January 3, 2001; revised July 6, 2011

This paper is based on a manuscript submitted to the International Conference of EBMM-2011, Shanghai, March: 11-13. The author wishes to acknowledge the kind support of King Fahd University of Petroleum and Minerals.

M-S. Oukil is with the Department of Management and Marketing, College of Industrial Management, King Fahd University of Petroleum and Minerals, Dhahran, 31261, Saudi Arabia. Tel: 0096638604285; Fax: 0096638602544; ()Oukil@kfupm.edu.sa) modern industrialization [1], witness the efforts and investments made during the last decades, but despite that some important shortcomings are awaiting serious attention from both Arab people and governments. To say that, infrastructural development is indeed necessary, but it should be accompanied by appropriate norms, attitudes, conducts and education. With the expected termination of oil and gas in the few coming decades, Arab countries will have to take lessons and emphasise innovation and entrepreneurship., and introduce changes in their business culture.

\section{LITERATURE REVIEW}

The notion, that innovation, entrepreneurship and knowledge, acquired through research and education, can drive economic growth, is currently well-grounded in economic research [2], [3], [4] and [5]. However, in the present author's view, enhancing growth requires not only public and private resources, but also a challenging business culture, enhanced by awareness and provision of various training programs in entrepreneurship and innovation.

In many developed countries, there is evidence that the rate of entrepreneurship increases with economic disappointments [6] or difficulties, implying that, as conditions get harder, people lean to initiate courses of action with the view to survive and beyond. Innovations are thus developed and opportunities can be spotted in both local and foreign markets, allowing competitiveness to be consolidated based on quality, cost-minimization and delivery [7], [8]. If doing business successfully requires knowledge, skills and certain types of behaviour, these can be gained in a professional way from cultural development and exposure to entrepreneurship. In developing and Arab countries, there are plenty of ideas and innovations that could generate economic growth and social development when taken care of.

At a macroeconomic level, it is argued that even in times of economic or financial crisis, organizations and countries should engage not only in incremental innovations, but also in breakthrough or even disruptive innovations [9]. This basically reflects the dynamism of economies and societies, where implementation requires positive patterns of management, work or performance. With regard to entrepreneurship, relevant theory and practice continually evolve, giving way to new models and practices. Promoting entrepreneurship and consolidating its links with technology readiness and acceptance, innovativeness, education and training, research and knowledge, and the social evolvement, are key characteristics of today's competitive economies and developed societies.

Theoretical frameworks, in which this paper fits in, include 
national innovations systems [10], [11], [12] and [13], the triple helix platform [14], innovation clusters [15], and entrepreneurship development [16]. The essence of all these frameworks is that when links between governments, industry and education are established, positive outcomes can be expected, with real impacts on growth and competitiveness. Based on these frameworks, innovation, entrepreneurship and education are today major research fields, indicating that performance is strongly linked with innovations, new businesses and knowledge, through education and research.

Quality entrepreneurship is also important for economic development, and much advocated by researchers. Koster [17], among others, refers to businesses generating the highest competitive advantage from exploiting technological innovations, and all entrepreneurial initiatives. However, what seems to be missing in such frameworks is again the cultural aspect, much associated with development and growth processes worldwide. This could probably be more critical today to developing and Arab countries, in particular, because of the generally low quality standards or norms.

In this paper, innovation refers to the emergence of various types of new organizational models, products, goods, materials, processes, techniques, systems or their improvements. Clearly, such outcomes will have no real and full impact unless ethics, behaviors, attitudes and cultural aspects are appropriate and adopted. Doing e-business could be very attractive, but when cheating, for instance, is involved, the economy and society will be losers.

By entrepreneurship, it is meant launching new ventures, and creating commercial or service businesses, technology-based firms, jobs, wealth and social welfare, but at the same time, taking care of the human factor [18] with regard to its adequate management. Availability of young people and competencies without care or chances of self-employment gives way to social unrests and even dangerous adventures, as indicated by recent waves of illegal immigration from developing to developed countries. Needless to say, that neither the best innovation strategies, nor the best entrepreneurship policies can generate positive and fair socio-economic and technological development when ethics and social responsibility are not considered. On the other hand, a great deal of waste could result from the marginalization of talents and disregard of initiatives based on experience and imagination.

Around the world, public authorities and business managers keep scanning the environments for new ideas, support small initiatives, and reinforce networking and linkages with technology and services providers [19]. For Arab countries, this is also critical, because while intelligence exists, skills of managing partnerships are particularly lacking, as another source of competitive advantage [20]. To remedy, a business culture, that takes care of all resources including time, and disposes people to take action to add economic, social and technological values, should therefore be urgently considered.

Discussing the case of Arab countries is worth for a number of reasons: First, there is not enough research on business culture and the effectiveness of the growth and competition policies in these countries. Second, the Arab world includes two interrelated sub-groups: one consists of oil-producing/exporting countries, and the other consists of non-oil producing countries. Despite some differences in cultural dimensions, resources and strategies, they all share a common aspiration to achieve the third millennium development goals. Third, as they are all much in need to improve their international growth and competitiveness prospects, they need to demonstrate real capabilities to change, and learn from proven theories and successful experiences, namely those fostering innovation, entrepreneurship through education and research. Countries, such as China, India, Malaysia and Singapore, for example, have gone a long way towards shifting into innovation-based entrepreneurship, thus easing the move towards a knowledge-based economy. These countries, and many others, have also put clear emphasis on innovation and entrepreneurship in their education systems, thus positively influencing national business culture.

\section{Progress And SHORTCOMINGS}

Geographically, the Arab world is quite large, and includes twenty two countries spread over North Africa, the Middle East and some parts of Asia. Although more and more physical progress is being made, Arab countries are generally described as significantly less innovative and competitive than the industrialized, newly industrializing and emerging countries, in particular. A number of reasons could explain this situation. First of all, it is argued that there is an acute shortage of qualified personnel with creativity, or innovativeness capability [21]. As a matter of fact, this is only partially true, since talents and competences do exist across the whole Arab world, but the trouble is that they are so often pulled by more motivating environments in other regions, namely the western countries. Noteworthy is that the Gulf countries region has been dealing with the problem, and has been attracting more and more of them, for financial as well as for other various reasons, such as social and religious closeness.

One of the serious growth policy problems in Arab countries is that while they focus their efforts to absorb unemployment, as much as possible, they tend to neglect efficiency, and often disregard local capabilities and the necessary appropriate context. This is to say that encouraging self-employment and creation of businesses is a good policy, but could be much better when channelled towards productive or value-added activities carried out in a proper manner. Surprisingly enough, modern technological systems have systematically been acquired by almost all Arab countries, but overall change in innovativeness and productivity is still low compared with the rest of the developing world.

Thanks to oil and derivatives, financial revenues allow them to maintain good living standards, thus re-inforcing the tendency towards easy-going work. The macro-picture is also quite positive in terms of networked readiness index, as shown by available data [22] in Table I. Compared to the highest figure of 5.85, scored by Denmark, the Arab countries' individual indexes are all above the mean, indicating that things are changing in a positive direction. For 
clarity purposes, the networked readiness index is generally used to refer to the effective use of information and communication technology (ITC) either by individuals, or organizations and governments with the view to generate wealth, and monitor regulations and relevant ICT infrastructures for the benefit of the economy and society.

TABLE I. ARAB NETWORKED READINESS INDEX 2008-2009

\begin{tabular}{lccc}
\hline Country & Index & Country & Index \\
\hline United Arab Emirates & 4.76 & Kuwait & 3.98 \\
Qatar & 4.68 & Egypt & 3.76 \\
Bahrain & 4.38 & Morocco & 3.59 \\
Tunisia & 4.34 & Syria & 3.41 \\
Saudi Arabia & 4.28 & Libya & 3.28 \\
Jordan & 4.19 & Algeria & 3.14 \\
Oman & 4.08 & Mauritania & 3.12 \\
\hline Source: World Economic Forum (2009). & &
\end{tabular}

Another indicator of progress in their favour can be found in the data concerning the share of high-technology exports as a percentage of total manufacturing exports. This is shown in the following Table II, where it can be seen that the countries on the left, all non-oil producing and exporting countries, are better performing than the countries on the right, all, except Lebanon, as oil-producing and exporting countries. This again suggests that potentialities exist in the Arab world to contribute to their growth and development.

TABLE II. SHARE OF HigH TECHNOLOGY EXPORT AS A \% OF TOTAL MANUFACTURING (2004) IN DESCENDENT ORDER

\begin{tabular}{llll}
\hline \multicolumn{1}{c}{ Top five } & \multicolumn{2}{c}{ Low five } \\
\hline & & & \\
Yemen & 12.97 & Bahrain & 2.73 \\
Morocco & 10.17 & Lebanon & 2.40 \\
Syria & 10.2 & Oman & 1.27 \\
Jordan & 5.32 & Algeria & 1.05 \\
Tunisia & 4.93 & Saudi Arabia & 0.82
\end{tabular}

Source: World Bank (2006).

However, in spite of all the public achievements, the particularly low level of entrepreneurial activity in Arab countries indicates that they are seriously lagging behind the great majority of countries. Even though the pillars for enabling policy frameworks are in place, but little effect is recorded. For example, in the United Arab Emirates, which is considered to be a leading country with regard to entrepreneurial development in the Arab world, only $2.7 \%$ of its population is engaged in entrepreneurial activities; this is indeed very low, in comparison with Indonesia $(19.3 \%)$ or Turkey (6.1\%) [23].

Also, in terms of "Firm Entrepreneurial Index", i.e., firms with innovative products or services and anticipating growth, used by the Global Entrepreneurship Monitor [24], no Arab country is well ranked, even among the smaller countries considered in the study. This clearly points to the fact that Arab countries have a long way to go with governments' big role in enabling all innovative sources, and fostering entrepreneurial initiatives. Besides that, effective macro-economic policies need to support the infrastructure that already exists and make it accessible to all. On the other hand, there is perhaps no need to invest in advanced technologies and systems without enhancing effectiveness and efficiency. Connectivity using information and technology systems and devices, for example, is socially very important, but could be more important when such systems and devices are utilized for improving productivity, and creating new goods and services.

At the microeconomic level, management tendency give less weight to innovative actions leading to gain competitive advantage, except in large firms with financial resources and R \& D activities. Even then, the large majority of industrial firms are much less competitive at the international level. In support, the number of Arab companies that gained international standards organization (ISO) certificates is indeed very low. In Saudi Arabia, for example, only 9\% of all manufacturing firms have gained ISO certification [25]. This suggests that not much importance is given to changes involving adoption of new models of management, best practices, innovation, entrepreneurship and knowledge. If there are countries and organizations, around the world, which moved quite rapidly from building investment and engineering capabilities to innovation capabilities, Arab countries, in general, seem long way away to reach innovation stages and advanced entrepreneurship development phases.

\section{EfFicient Management of Businesses AND People}

Business organizations and competencies are necessary for any evolving economy. Specifically, creating more and new businesses is particularly important in order to capture and benefit from the ideas and knowledge held by people and talents on particular. Turning ideas and knowledge into efficient and practical outcomes is the main mission of modern organizations of all sizes. Sometimes, they may have to become knowledge-producing firms [26] to secure the flow of knowledge, when international access to knowledge is prohibited for one reason or another. Alternatively, networking and joining innovation clusters can help in sharing knowledge and developing joint innovations, and therefore reducing the lack of innovative ideas, as source of development and growth. In particular, developing and Arab countries and organizations should therefore exploit all possible channels, and professionally monitor their joint efforts with others.

When they are self-employed, and manage their own businesses, people contribute to the welfare of the economy and society by exploiting their innovative ideas. As talents employed by public or private firms, people can contribute to increasing performance and competitiveness, but going entrepreneurial will benefit them, as well as the economy and society, at large. According to a leading management author [27], innovation and entrepreneurship are necessary if such objectives are to be achieved by either nations or organizations. In both private and public organizations, human resources, therefore, need to be appropriately managed, overcome distance power barriers, and freed from constraints of doing business.

Individuals who can develop technological innovations are people with science and engineering backgrounds. Faculty, researchers, university students and graduates and employees in these fields form the bulk of inventors and/or innovators in the population. However, if this profile is required for inventiveness and innovativeness, new technical ideas will 
remain of limited use until businesses are created to exploit them, hence the need for business-based training or education When individuals launch their start-up firms, they should add value to existing assets and create new capital ventures that are needed for growth. This is where schooling-based business, management and marketing knowledge become therefore essential.

In Arab countries, a great deal of effort is devoted to the creation of small enterprises per se. In their development policies, governments usually publish figures showing the number of firms created, and the volume of jobs generated or expected. Whereas these outcomes are very important, more important are the contributions made to growth and competitiveness by efficiency, and the quality management of human resources and initiatives. Where corruption, harassment and bureaucracy prevail, little can be expected in terms of up-grading productivity and making use of talents. Arab countries do not escape this situation, and the actual balance between brain drain and brain gain of talents and entrepreneurs is not yet in their favour.

\section{THE INADEQUATE UNDERSTANDING OF COMPETITIVENESS}

Historically, Arabs have been known to engage in agricultural, traditional and trade activities, in particular. The corresponding goods exchanged for centuries have thus affected the Arab business mentality before the discovery of oil. After that, the majority of Arab countries have gone through much transformation, to become major producers / exporters of oil and gas in the world.

Such transformation has also resulted in different economic structures in those countries. While many of them have developed strong state oil sectors, only a few of them have voluntarily involved the private sector in the development process, except in particular areas, such as commerce, real estate, tourism and services. Outside the oil sector, private investments have been allowed much later, as is the case for example in transportation, education, other services and manufacturing. Today, the great majority of Arab firms are owned by the governments. Small businesses are emerging but very slowly.

Truly, the notion of competitiveness seems to have been inadequately interpreted in the Arab world. Many people, managers and officials, tend to understand it exclusively in its macro-economic sense, i.e., referring to the ease with which private businesses can be created. In this case, competitiveness does refer to the investment climate and freedom to do business. In this context, many Arab countries do seem doing well, due to improvements in their ranking as per the global competitiveness index [28], but this is, however, just one side of the coin.

In effective terms, competitiveness is mainly achieved when countries and organizations gain consistent competitive advantage, through high quality outputs and low production costs. To reach this stage, they need to move rapidly through four types of technological capabilities: investment, engineering, production and innovation [29]. The last stage of innovation is particularly important as it demonstrates the capability to differentiate output from competitors, thus resulting in improvements of productivity, which gives real sense to competitiveness. Whether incremental or disruptive, technological innovations are but the fuel of modern growth and competitiveness [30].

Everywhere and in Arab countries, building effective competitiveness will require but good management of three inter-related areas, i.e., innovation, entrepreneurship and knowledge production or use [31]. For one thing, the links between all these three areas provide necessary ingredients for shifting from traditionally trade-based economies into productive and innovative ones. While individually, Arab countries differ in their recovery from the last financial crisis [32], very few of them appear to successfully face the challenges with regard to long term strategies, and rapid transformations in ways of thinking and doing business.

\section{The Prevailing Business Culture}

Key elements of business culture may include management styles, meetings patterns, team working, communications styles, and time management. In doing business, cultural characteristics make a difference [33] as they influence the outcomes. This sustains the idea that the development of innovative and entrepreneurial activities depends on the type of culture prevailing in organizations and countries. For instance, managers with adaptive cultures and strong values can perform well and benefit from the loyalty of employees and customers [34]. Where work is also valued and quality is rewarded, initiatives can emerge, and consequently businesses flourish. On the opposite, where the investment climate is constraining, and behaviour, habits and customs are counterproductive, consequences will be negative and produce very limited or no progress at all.

In general, Arabs are said to be keen entrepreneurs but with a tradition of trading rather than manufacturing [35]. Hence, the urgent need to enhance risk taking attitudes among Arab employees, managers, and investors, in general, and students, graduates, scientists and technologist, in particular. Entrepreneurship exposure or awareness about the world of business, and respects of standards could provide wider opportunities to learn and therefore create small non-traditional businesses. For higher growth rates, Arab countries therefore have no choice but to introduce changes in their business models and education. Actually, the shift to technopreneurship or innovation-based entrepreneurship seems to be much constrained by a strong preference for activities that produce rapid returns [36]. This is the case in trade or commerce, services and the stock exchange that attract Arab investors. Emergence of more high-tech start-ups will be possible when productive skills and entrepreneurial spirits are taught and promoted.

A number of important obstacles must, of course, be removed. To start with, as a lot of time is generally wasted and better time-management is an absolute necessity for Arab people and organizations aspiring for better prospects. Higher quality work and performance also need to be monitored, through recourse to best practices and implementation of adequate procedures and standards. In doing business, risk taking needs to be supported and encouraged through learning from mistakes at all levels. 
The public and private money surplus that has been accumulated over many decades should be used to generate more wealth and growth, by channeling it more into productive activities, innovation-based activities, and knowledge-based outputs, in various actors. Because, only then can development objectives be more easily attained. Needless to stress that as corruption is widely spread in both public and private Arab organizations, its quick removal must be decisive [37] by highly determined political and legal measures.

\section{The PARTicular Role of Higher EdUCATION INSTITUTIONS}

The level of academic entrepreneurship in the national innovation system may matter in the development process. While in the developed, newly industrializing and emerging countries, more and more universities are becoming entrepreneurial [36], in Arab countries this movement is very slow and much reduced to a certain regions, namely the Middle East countries. Becoming entrepreneurial involves not only the creation of new businesses, but also the appropriate environment, incentives and relevant education and training. In Arab countries, small enterprises and private businesses are encouraged, but the necessary accompanying measures are often absent or remain inadequate. In the education field, extremely few private universities or institutes provide teaching and training that match the demand for new business skills, knowledge and inspiration. On the other hand, the great majority of public institutions do not up-date their curricula to match international emphasis on entrepreneurship education.

Future as well as present Arab young business leaders and entrepreneurs need to be educated and trained, particularly when it comes to how to successfully convert ideas, technologies and innovations into commercialized outputs, and sold in local and international markets. So far, the efforts made are rather slow, and limited to establishing administrative infrastructures, or simply to the creation of businesses in the tertiary sector, with the view to absorbing unemployment. Apart from Jordan, the United Arab Emirates, Lebanon, Bahrain and Saudi Arabia, in other Arab countries, entrepreneurship education is severely lacking, at very early stage or no much engaging the available potentialities. One reason could be because education institutions are not truly or fully integrated into the world of industry. Besides that, interest in and practices of business still remain a matter of personal resourcefulness, which depends on an individual's traits or characteristics and background. For Arab countries to become internationally competitive, trainees and students should be taught entrepreneurship in local as well as in a global context [38]. If seriously undertaken, the drive towards knowledge-based economies and societies should speed up this shift, particularly when higher education institutions in the Arab world take the lead and, thus regain their enlightening and forming roles.

\section{SUMMING UP AND CONCLUSION}

Theory and studies provide convincing arguments, as well as valid evidence, that where innovation, entrepreneurship, education and research are together enhanced, economic performance is strong. This implies that, in general, the higher the levels of innovation and entrepreneurship in economies and organizations, the higher are the expected levels of growth and competitiveness.

However, where business culture is not much evolved, the above results may not be easily obtainable. Developing an entrepreneurial mindset will consequently require public awareness, engagement and active interventions of governments and education institutions. This will give a chance to citizens to be exposed to the world of entrepreneurship, and provides confidence to would be hesitant to concretize their ideas or dreams on the basis of up-dated norms and best practices. Business firms will, thus, benefit a great deal from interactions with higher education and research institutions and from clusters with both private and public firms in order to solve problems innovatively.

If better performances are to be achieved, businesses in the Arab world should be more diversified and innovation-based. In support of this, there is the fact that technology acceptance is widely spread among the young and intellectual communities. These need to be taught and supported to engage more in value-adding activities. Those working in public or private organizations should also be trained to think entrepreneurially, so that they can contribute more positively.

Available data show that Arab countries are all making considerable efforts to close the various gaps with the advanced countries, in all fields and spheres. In recent years, a number of Arab countries have taken some offensive actions to move towards value-adding exports, and developing high-tech and even science-based industries. This suggests that these countries have real potential to grow and become internationally competitive. The need to ensure a good fit between physical resources and non-materialized aspects, included in culture, could give these countries better chances to successfully integrate the international world of business. Practical investigations in each Arab country will, of course, help in drawing more sound conclusions.

\section{REFERENCES}

[1] M-S. Oukil, "A Development Perspective of Technology-based Entrepreneurship In the Middle East and North Africa", Annals of Innovation and Entrepreneurship, vol. 2, no. 1, pp. 1-10, 2011.

[2] U. D. Hann, "A Hotbed for Entrepreneurship and Innovation" in Hulsink and Dons (Eds.) Pathways to High-tech Valleys and Research Triangles: Innovative Entrepreneurship, Knowledge Transfer and Cluster Formation in Europe and the US, Spinger, pp. 79-97, 2008.

[3] M, Trajtenberg, "Innovation in Israel 1968-1997: A comparative analysis using patent data," Research Policy, vol. 30, 2001, pp. 363-389, doi: 10.1016/S0048-7333(00)00089-5

[4] E. Helpman, The Mystery of Economic Growth, Belknap Press. Cambridge, 2004.

[5] D. B. Audretsch, and M. Keilbach, "Entrepreneurship Capital and Economic Performance," Regional Studies, vol. 38, no. 8, pp. 949-959, 2004, available at: http://ssrn.com/abstract $=1506826$.

[6] Aacsb, 2009: available at: http://www.aacsb.edu/publications/enewsline/entrepren.asp,

[7] M. E. Porter, "Clusters and the New Economics of Competition", Harvard Business Review, November-December, pp.77-90, 1998, reprint 98609.

[8] H. L. Lee, The triple-A supply chain. Harvard Business Review, 82, 10, October, pp. 102-112, 2004.

[9] P.J.H. Schoemaker, "Why an Economic Crisis Could Be the Right Time for Companies to Engage in 'Disruptive Innovation", 2008, 
available

http://knowledge. wharton.upenn.edu/article.cfm?articleid $=2086$

[10] R. Nelson (ed.), National Innovation Systems. A Comparative Analysis, Oxford University Press, New York/Oxford, 1993.

[11] P. Patel and K. Pavitt, "National Innovation Systems: Why they are important and how they might be measured and compared", Economics of Innovation and New technology, vol. 3, no.1, pp. 77-95, 1994, ISSN: 10438599.

[12] B-A. Lundvall, (ed.), National Systems of Innovation - Towards a Theory of Innovation and Interactive Learning. London, Pinter Publishers, 1992.

[13] C. Freeman, "The 'National Innovation System' in Historical Perspective", Cambridge Journal of Economics, vol. 19, pp. 5-24, 1995, downloaded from: oxfordjournals.org (kfupm).

[14] L. Leydesdorff, and H. Etzkowitz, "The Triple Helix as a Model for Innovation Studies", Science \& Public Policy, vol. 25, no. 3, pp.195-203, 1998, doi: 10.1108/14636680710821061.

[15] Reference [6].

[16] B. Johansson, C. Karlinsson, and R. S.Stough (Eds.), The Emerging Digital Economy: Entrepreneurship Clusters and Policy, Springer, Berlin, 2006.

[17] S. Koster, "Entrepreneruship and Economic Development in a Developing Country," Journal of Entrepreneurship, vol. 17, no. 2, pp. 117-137, 2008, doi: 10.1177/097135570801700202.

[18] T. N. Sinha, "Humans Factors in Entrepreneurship Effectiveness", Journal of Entrepreneurship, vol. 5, no. 1, pp.23-39, 1996, doi: $10.1177 / 097135579600500102$.

[19] H. Zafar, "Information Technology Led Innovativeness - UAE perspective," 18th Global Conference on Flexible Systems Management, New Jersey, June: 14-16, 2008.

[20] A. MacComark, Best Practices of Global Innovators, 2007, available at: http://hbswk.hbs.edu/item/5750.html

[21] Arab Innovation Index, Price Waterhouse Coopers in partnership with Moutamarat and INSEAD, December, 2006.

[22] World Economic Forum, The Global Information technology Report: Mobility in a networked world, Dutta, J and Mia, I, World Economic Forum and UNSEAD, 2009.

[23] Buss-Allen-Hamilton, http://www.boozallen.com/news/38284437.

2007.

4] GEM - Global Entrepreneurship Monitoring (2003) (2004) (2005) http://www.entre-ed.org/_contact/mem04.htm. Accessed January 2008

[25] H. A. E. Magd, "An investigation of ISO 9000 adoption in Saudi Arabia," Managerial Auditing Journal, vol. 21, no. 2, pp.132-147, 2006 doi: $10.1108 / 02686900610639284$.

[26] I. Nonaka, and H. Takeuchi, The Knowledge-Creating Company, Oxford University Press, 1995.

[27] P. F. Drucker, Innovation and Entrepreneurship, New York: Collins, 2006.

[28] G.C.I (Global Competitiveness Index). 2007-2008. Global Competitiveness Index and Comparisons 2007-2008. http://www.weforum.org/pdf/gcr/2008/rankings.pdf

[29] C. L. Dahlman, B. Ross-Larson, and L. E. Westphal, L.E. "Managing Technological Development: Lessons from the NICs," World Development, vol. 15, no. 6, pp. 759-75, 1987.
[30] Reference [6].

[31] M-S. Oukil, "Building Effective Competitiveness in the Arab World," 2nd International Conference, University of Kuwait, 13-14 December, 2006.

[32] E. Lanchovichina, L. Moottaghi, K. Carrey, N. Spivak, S. farazi, and A. Silwal, @Recovering from the Crisis, The World Bank, Washington. D. C. 2010 .

[33] D. H. B. Welsh and P. Raven, "A.n exploratory study of SME Management in the Middle East," International Journal of Entrepreneurship and Small Business, 1(1/2), pp. 121-135, 2004, doi: .10.1504/IJESB.2004.005380.

[34] J. L. Heskett, W. E. Sasser, and J.Wheeler, Ownership Quotient: Putting the Service Profit Chain to Work for Unbeatable Competitive Advantage, Boston: Harvard Business Publishing, 2008.

[35] G. Rice, The challenge of creativity and culture: a framework for analysis with application to Arabian Gulf firms, Elsevier Science Ltd, 2003.

[36] R. Suwait, "Comparative study of political corruption in some Arab countries: The case of governments, entreprises, organizations and individuals", Aqsa University Review, vol. 13, no. 1, pp. 158-211, 2009.

[37] M-S. Oukil, "The Development of Entrepreneurship in MENA countries: An Overview of Constraints and Perspectives," in Allem (Ed.), Business Excellence and Competitiveness in the Middle East and North Africa, London, pp. 309-318, 2007.

[38] C. Jones, and J. English, "A contemporary approach to entrepreneurship education", Education + Training, vol. 46, no. 8/9, pp. 416-423, 2004, doi: 10.1108/00400910410569533.

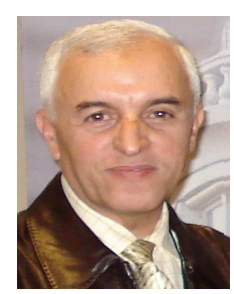

M-Said Oukil is born in Algeria. After obtaining his Bachelor degree from Algiers University, he went to Great Britain, where he gained his Master degree (University of Sussex) and his PhD (University of Strathclyde) in Economics of research and development. His is actually working in Saudi Arabia (King Fahd University of Petroleum and Minerals -Colle of Industrial management - Department of Management and Market. His reaserch work focusses on innovation and entreprenewurship.

His is actually working as a Visiting Professor in Saudi Arabia (King Fahd University of Petroleum and Minerals -College of Industrial management - Department of Management and Marketing). His latest book (forcoming) is on technological innovation with particular reference to the Arab world. His prsent reaserch work focusses on innovation and entreprenewurship

Prof. Oukil is an editorial board member in the following: Annals of Innovation and Entrepreneurship; International Journal of Business \& management; Europena Journal of Scientific Research. He has been an invited member in the Indec Copernicus.com. He is an Editor of the African Journal of Marketing Management. 